\title{
Poverty cannot be inhaled and it is not a genetic condition. How can it be associated with chronic airflow obstruction?
}

\author{
Carlos A. Torres-Duque \\ Affiliation: Research Department, Fundación Neumológica Colombiana, Bogotá, Colombia.
}

Correspondence: Carlos A. Torres-Duque, Fundación Neumológica Colombiana, Carrera 13B No. 161-85, Carrera 13B, 101131 Bogotá, D.C., Colombia. E-mail: ctorresaneumologica.org

@ERSpublications

Poverty is independently associated with chronic airflow obstruction: underlying factors need to be investigated http://ow.ly/Juux30c0MnA

Cite this article as: Torres-Duque CA. Poverty cannot be inhaled and it is not a genetic condition. How can it be associated with chronic airflow obstruction? Eur Respir J 2017; 49: 1700823 [https://doi.org/ 10.1183/13993003.00823-2017].

\begin{abstract}
Chronic airflow obstruction (CAO) does not mean chronic obstructive pulmonary disease (COPD) but it is one of its defining characteristics [1]. According to the global strategy for diagnosis, management and prevention of obstructive lung diseases, COPD is usually caused by significant exposure to noxious particles or gases. The report highlights that airflow obstruction in COPD is the result of complex interactions between exposures (mainly smoking, biomass fuels and occupational dusts) and host factors, and postulates that COPD could be a relatively specific and separable disease in nosological terms.

In epidemiologic studies there are a wide variety of definitions of COPD, as well as measurements of it and of its risk factors, making comparison difficult [2]. Since airflow obstruction assessed by spirometry is an objective measure, and given that we are looking for comparability, persistent post-bronchodilator airflow obstruction (assumed to be CAO) is accepted as an epidemiologic definition of COPD. However, airflow obstruction is only one of the traits of COPD and people included in epidemiologic studies under this functional definition are an extremely heterogeneous group, where many diseases and conditions different to COPD are likely to have been included [3, 4]. Beyond the controversy about which diseases, syndromes or pathological conditions should and should not be included under the term COPD, these concepts are important for understanding that risk factors established in epidemiologic studies of CAO in people older than 40 years might not exactly be risk factors for COPD (a term better used in an appropriate clinical context [5]), and for interpreting the results of population studies on CAO and COPD.

In this issue of the European Respiratory Journal (ERJ), TownEND et al. [6] present the results of an interesting study aimed at evaluating the possible association between poverty and CAO. Adjusting by age, sex, body mass index (BMI), smoking, passive smoking, dusty job, family history of breathing problems, childhood hospitalisation for breathing problems, history of asthma, open fire exposure ( $>20$ years) and history of tuberculosis (TB), the wealth score was directly related to forced expiratory volume in $1 \mathrm{~s} /$ forced vital capacity ratio (FEV1/FVC). In the same way, the prevalence of obstruction (FEV1/FVC $<$ lower limit of normal (LLN)) fell by approximately $9 \%$ for each point of increase in the wealth score. These findings mean that poverty is independently associated with $\mathrm{CAO}$ and is a strong predictor of its presence.
\end{abstract}

Received: April 202017 | Accepted after revision: May 232017

Conflict of interest: None declared.

Copyright @ERS 2017 
This paper is part of the Burden of Obstructive Lung Disease (BOLD) study, the largest initiative in the world on prevalence and risk factors associated with CAO and COPD [7, 8]. The sample of 9255 adults was taken from 12 sites belonging to 11 countries. The authors recognise that although the sites covered a broad range of socio-economic conditions, they could be biased towards low-resource (poor) sites. However, taking into account that poverty was evaluated at an individual level, with a wide range of scores among a significant number of the participants, this does not seem to be a strong limitation.

One concern could be the method used for evaluating poverty in this study, which is based only on the ownership of ten household assets. In general terms, poverty can be measured by income, expenditure or consumption, or by various combinations thereof. The Multidimensional Poverty Index proposed by the Human Development Program includes three dimensions: health, education and standard of living (evaluated by household cooking fuel, toilet, water, electricity, floor and assets). An alternative approach to poverty which is frequently used in health studies is the assessment of socioeconomic status (SES), a composite measure of a person's economic and social position generally based on income, occupation, education level, and home and neighbourhood conditions and environment [9]. Although some authors have questioned the assets-based methods [10], the wealth score used in Townend's study has shown close correlation with the education level and gross national income per capita of the country [11].

Several studies have also shown a strong correlation between low SES (assumed to be poverty) and a higher prevalence of CAO/COPD, as well worse outcomes for COPD [12, 13]. Environmental risk factors for developing COPD, including tobacco smoking, occupational pollutants, and outdoor and indoor pollution exposure (mainly biomass fuels) [12] are more common in low SES people. Previous reports from the BOLD study and on the Global Burden of Disease programme have shown that poverty is also related to restrictive ventilatory defect and higher mortality from COPD [14, 15].

Smoking, dusty job conditions, TB and asthma, all of which were significantly associated with obstruction in the Townend study, have also been associated with low SES and poverty [12]. Although the poorest people cannot afford tobacco products, and the association between income and smoking is complex, in general there is an inverse relationship between income level and the prevalence of tobacco use and its related consequences [16]. SES based on occupation has been related to COPD prevalence: manual workers and non-manual assistants (assumed to be lower SES) having a significantly higher prevalence of COPD than professionals [17]. TB, a disease clearly related to poverty, has been strongly associated with the development of CAO [18]. However, as a specific disease, the obstructive disease associated with TB might not be included under the umbrella of the term COPD. It has been reported that asthma prevalence is higher in groups of lower SES [19] and that chronic exposure to a low-income environment from birth is also associated with the development of persistent asthma [20].

Taking into account the fact that household use of solid fuels is one of the indicators most frequently included in multidimensional scales of poverty, and one of the main contributors to indoor air pollution in developing countries, it is noteworthy that there was no association between obstruction and open fire exposure ( $\geqslant 20$ years) in this study, like previous BOLD publications [8]. Conversely, other population-based studies, such as the PREPOCOL (Prevalencia de EPOC en Colombia) study [21], and case-control studies consolidated in systematic reviews and meta-analysis [22], have shown a significant association between solid fuel exposure (including biomass) and CAO/COPD. These contradictory results could partially be explained by the lack of standardisation in measurement of long-term exposure to biomass fuels in cross-sectional studies and the lack of knowledge of the exposure-response curves [23].

Since poverty and low SES cannot cause CAO or COPD per se, the main challenge to be derived from these studies and that of Townend is to explain which factors underlying poverty and low SES are the real causes or conditioners of CAO or COPD in people older than 40 years. It is inferred that other factors additional to the confounders mentioned could explain $\mathrm{CAO}$ and either they were not included in the analysis (not evaluated) or were not reliably evaluated. This is a limitation of cross-sectional studies that base most of their information on self-reports. The authors properly recognise this limitation.

Probably the most difficult factors to evaluate in this type of study (performed with people $\geqslant 40$ years old) are the prenatal or perinatal conditions and the childhood diseases and exposures that can be related to early development of airflow obstruction and low adult pulmonary function and CAO [4, 24-26]. These include maternal events and exposures, genetic constitution, low birth weight, early asthma, respiratory infections and early exposure to indoor and outdoor air pollution. Some of these factors can also be associated with poverty or low SES $[12,24]$. It is clear that current poverty, as assessed by TownEND et al. [6], does not imply poverty at prenatal or childhood stages, but it is the most probable situation.

Although low birth weight (LBW) is mainly associated in certain studies with restrictive impairment in adulthood, and only weakly with airflow obstruction, several studies show an association between LBW (a 
condition clearly related to poverty) and the early development of asthma [27]. Maternal and early life exposure to smoking and biomass fuels, two frequent conditions for people of low SES, are related to LBW, higher risk of asthma $[24,28]$ and late airflow obstruction [29]. Early bronchial hyper-responsiveness and asthma have also been associated with late airflow obstruction [12, 24, 30].

Genetic constitution could be influenced by maternal events and exposures that are more frequent at low SES $[24,29,31]$ and lower respiratory infections, mainly pneumonia, also occur more frequently in poor children and have been consistently related to the development of COPD [32-34]. Some conditions inherent to poverty, such as LBW, crowding, indoor air pollution, incomplete immunisation and undernutrition, have been associated with an increased risk of lower respiratory infections in childhood. Global urban air pollution levels have increased by $8 \%$ despite improvements in some regions, with the highest urban air pollution levels being in low- and middle-income countries [35]. Although the evidence is not consistent, some studies have shown an association between outdoor air pollution and the development of COPD.

The results of the Townend study are a stimulus to investigate new factors and mechanisms, many of which occur in the prenatal and early stages of life, related to the development of airway obstruction in people (especially in developing countries) who are living in poverty or who were previously exposed to it. The study is also an opportunity to encourage research on the better characterisation of pathologic conditions that share $\mathrm{CAO}$ as a functional trait but which have significant differences, including diagnosis, prognosis and management, to smoking-related COPD [36]. The use of a functional characteristic as the only defining criterion of COPD (at the epidemiological level) or as the main diagnostic criterion of COPD (at the clinical level) makes weak not only the definition of the disease in nosological terms but also the use of the term clinical phenotype. In some cases, what we might be defining as a different phenotype may correspond more appropriately to a different disease.

\section{References}

1 Global strategy for diagnosis, management and prevention of chronic obstructive pulmonary disease (2017 report). Global Initiative for Chronic Obstructive Lung Disease (GOLD), 2017. http://goldcopd.org/ gold-2017-global-strategy-diagnosis-management-prevention-copd/ Date last accessed: March 25, 2017.

2 Bakke PS, Rönmark E, Eagan T, et al. Recommendations for epidemiological studies on COPD. Eur Respir J 2011; 38: 1261-1277.

3 Postma DS, Brusselle G, Bush A, et al. I have taken my umbrella, so of course it does not rain. Thorax 2012; 67: 88-89.

4 Rennard SI, Drummond MB. Early chronic obstructive pulmonary disease: definition, assessment, and prevention. Lancet 2015; 385: 1778-1788.

5 Agusti A, Vestbo J. Current controversies and future perspectives in chronic obstructive pulmonary disease. Am J Respir Crit Care Med 2011; 184: 507-513.

6 Townend J, Minelli C, Mortimer K, et al. The association between chronic airflow obstruction and poverty in 12 sites of the multinational BOLD study. Eur Respir J 2017 49: 1601880.

7 The Burden of Obstructive Lung Disease (BOLD) Initiative. BOLD initiative sites. www.boldstudy.org/sites.html Date last accessed: May 25, 2017.

8 The Burden of Obstructive Lung Disease (BOLD) Initiative. BOLD initiative publications. www.boldstudy.org/ Publications.html Date last accessed: May 25, 2017.

9 Duncan GJ, Daly MC, McDonough P, et al. Optimal indicators of socioeconomic status for health research. Am J Public Health 2002; 92: 1151-1157.

10 Foreit KGF, Schreiner M. Comparing alternative measures of poverty: assets-based wealth index $v s$. expenditures-based poverty score (working paper series). Chapel Hill, MEASURE Evaluation PRH, 2011. www. measureevaluation.org/resources/publications/wp-11-123 Date last accessed: May 25, 2017.

11 Townend J, Minelli C, Harrabi I, et al. Development of an international scale of socio-economic position based on household assets. Emerg Themes Epidemiol 2015; 12: 13.

12 Pleasants RA, Riley IL, Mannino DM. Defining and targeting health disparities in chronic obstructive pulmonary disease. Int J Chron Obstruct Pulmon Dis 2016; 11: 2475-2496.

13 Kanervisto M, Vasankari T, Laitinen T, et al. Low socioeconomic status is associated with chronic obstructive airway diseases. Respir Med 2011; 105: 1140-1146.

14 Burney P, Jithoo A, Kato B, et al. Chronic obstructive pulmonary disease mortality and prevalence: the associations with smoking and poverty-a BOLD analysis. Thorax 2014; 69: 465-473.

15 Burney PG, Patel J, Newson R, et al. Global and regional trends in COPD mortality, 1990-2010. Eur Respir J 2015; 45: 1239-1247.

16 World Health Organization. Systematic review of the link between tobacco and poverty. Geneva, World Health Organization, 2011. http://apps.who.int/iris/bitstream/10665/44453/1/9789241500548_eng.pdf Date last accessed: May 25, 2017.

17 Kainu A, Rouhos A, Sovijärvi A, et al. COPD in Helsinki, Finland: socioeconomic status based on occupation has an important impact on prevalence. Scand J Public Health 2013; 41: 570-578.

18 Allwood BW, Myer L, Bateman ED. A systematic review of the association between pulmonary tuberculosis and the development of chronic airflow obstruction in adults. Respiration 2013; 86: 76-85.

19 Basagaña X, Sunyer J, Kogevinas M, et al. Socioeconomic status and asthma prevalence in young adults: the European Community respiratory health survey. Am J Epidemiol 2004; 160: 178-188. 
20 Kozyrskyj AL, Kendall GE, Jacoby P, et al. Association between socioeconomic status and the development of asthma: analyses of income trajectories. Am J Public Health 2010; 100: 540-546.

21 Caballero A, Torres-Duque CA, Jaramillo C, et al. Prevalence of COPD in five Colombian cities situated at low, medium, and high altitude (PREPOCOL study). Chest 2008; 133: 343-349.

22 Kurmi OP, Semple S, Simkhada P, et al. COPD and chronic bronchitis risk of indoor air pollution from solid fuel: a systematic review and meta-analysis. Thorax 2010; 65: 221-228.

23 Torres-Duque C, Maldonado D, Pérez-Padilla R, et al. Biomass fuels and respiratory diseases: a review of the evidence. Proc Am Thorac Soc 2008; 5: 577-590.

24 Postma DS, Bush A, van den Berge M. Risk factors and early origins of chronic obstructive pulmonary disease. Lancet 2015; 385: 899-909.

25 Eisner MD, Anthonisen N, Coultas D, et al. An official American Thoracic Society public policy statement: novel risk factors and the global burden of chronic obstructive pulmonary disease. Am J Respir Crit Care Med 2010; 182: 693-718.

26 Stocks J, Sonnappa S. Early life influences on the development of chronic obstructive pulmonary disease. Ther Adv Respir Dis 2013; 7: 161-173.

27 Johnson RC, Schoeni RF. Early-life origins of adult disease: national longitudinal population-based study of the United States. Am J Public Health 2011; 101: 2317-2324.

28 Pope DP, Mishra V, Thompson L, et al. Risk of low birth weight and stillbirth associated with indoor air pollution from solid fuel use in developing countries. Epidemiol Rev 2010; 32: 70-81.

29 Hylkema MN, Blacquiere MJ. Intrauterine effects of maternal smoking on sensitization, asthma, and chronic obstructive pulmonary disease. Proc Am Thorac Soc 2009; 6: 660-662.

30 Tagiyeva N, Devereux G, Fielding S, et al. Outcomes of childhood asthma and wheezy bronchitis. A 50-year cohort study. Am J Respir Crit Care Med 2016; 193: 23-30.

31 Wadhwa PD, Buss C, Entringer S, et al. Developmental origins of health and disease: brief history of the approach and current focus on epigenetic mechanisms. Semin Reprod Med 2009; 27: 358-368.

32 Lopez Bernal JA, Upton MN, Henderson AJ, et al. Lower respiratory tract infection in the first year of life is associated with worse lung function in adult life: prospective results from the Barry Caerphilly Growth study. Ann Epidemiol 2013; 23: 422-427.

33 Svanes C, Sunyer J, Plana E, et al. Early life origins of chronic obstructive pulmonary disease. Thorax 2010; 65: 14-20.

34 Gold DR, Tager IB, Weiss ST, et al. Acute lower respiratory illness in childhood as a predictor of lung function and chronic respiratory symptoms. Am Rev Respir Dis 1989; 140: 877-884.

35 World Health Organization. Air pollution levels rising in many of the world's poorest cities. Geneva, World Health Organization, 2016. www.who.int/mediacentre/news/releases/2016/air-pollution-rising/en/ Date last updated: May 12, 2016. Date last accessed: May 25, 2017

36 Torres-Duque CA, García-Rodriguez MC, González-García M. Is chronic obstructive pulmonary disease caused by wood smoke a different phenotype or a different entity? Arch Bronconeumol 2016; 52: 425-431. 